\title{
Validity of a method for the self-screening of cardiovascular risk
}

This article was published in the following Dove Press journal:

Clinical Epidemiology

María Barroso, ${ }^{1-3}$ Silvia Pérez-

Fernández, ${ }^{1,4}$ M Mar Vila, ${ }^{1,4,5}$

M Dolors Zomeño, 6,7 Ruth

Martí-Lluch, ${ }^{8}$ Ferran Cordon, ${ }^{9}$

Rafel Ramos, $8,10,11$ Roberto

Elosua, ${ }^{1,4}$ Irene R Degano, 1,4

Montse Fitó, 5,12 Carmen

Cabezas, ${ }^{13}$ Gemma Salvador, ${ }^{13}$

Conxa Castell, ${ }^{13}$ María Grau',4,14

'Cardiovascular Epidemiology and Genetics Research Group, IMIM-Hospital del Mar Research Institute, ${ }^{2}$ Centre d'Atenció

Primària La Marina, Direcció d'Atenció Primària Barcelona, Institut Català de la Salut, ${ }^{3}$ Department of Pediatrics, Obstetrics, Gynecology and Preventive Medicine,

School of Medicine, Autonomous University of Barcelona, ${ }^{4}$ Consortium for Biomedical

Research in Cardiovascular Disease (CIBERCV), ${ }^{5}$ Department of Mathematics and Computer Science, University of

Barcelona, ${ }^{6} \mathrm{Cardiovascular} \mathrm{Risk}$ and

Nutrition, IMIM-Hospital del Mar Research Institute, ' 5 chool of Health Sciences,

Blanquerna-Ramon Llull University,

Barcelona, Spain; ${ }^{8}$ Unitat de Suport a la

Recerca de Girona, Institut Universitari d'Investigació en Atenció Primària Jordi Gol, ' ${ }^{\circ}$ entre d'Atenció Primària Montilivi, Direcció d'Atenció Primària Girona, Institut Català de la Salut, ${ }^{10}$ Department of Medical Sciences, School of Medicine, University of Girona, "Girona Biomedical Research Institute, Girona, Spain; ${ }^{12}$ Consortium for Biomedical Research in Obesity and Nutrition (CIBEROBN), ${ }^{13} \mathrm{Catalan}$ Agency of Public Health, ${ }^{14}$ Department of Medicine, University of Barcelona, Barcelona, Spain

Correspondence: María Grau Cardiovascular Epidemiology and Genetics, IMIM-Hospital del Mar Research Institute, Barcelona E-08003, Spain

Tel +34933160800

Fax+34933160796

Emailmgrau@imim.es
Background: The validity of a cardiovascular risk self-screening method was assessed. The results obtained for self-measurement of blood pressure, a point-of-care system's assessment of lipid profile and glycated hemoglobin, and a self-administered questionnaire (sex, age, diabetes, tobacco consumption) were compared with the standard screening (gold standard) conducted by a health professional.

Methods: Crossover clinical trial on a population-based sample from Girona (north-eastern Spain), aged 35-74, with no cardiovascular disease at recruitment. Participants were randomized to one of the two risk assessment sequences (standard screening followed by self-screening or vice versa). Cardiovascular risk was estimated with the Framingham-REGICOR function. Concordance between methods was estimated with the intraclass correlation coefficient (ICC). Sensitivity, specificity, and positive and negative predictive values were estimated, considering 5\% cardiovascular risk as the cutoff point. ClinicalTrials.gov Registration \#NCT02373319. Clinical Research Ethic Committee of the Parc de Salut Mar Registration \#2014/5815/I.

Results: The median cardiovascular risk in men was 2.56 (interquartile range: $1.42-4.35$ ) estimated by standard methods and $2.25(1.28-4.07)$ by self-screening with ICC $=0.92(95 \%$ CI: $0.90-0.93)$. In women, the cardiovascular risk was $1.14(0.61-2.10)$ by standard methods and $1.10(0.56-2.00)$ by self-screening, with $\mathrm{ICC}=0.89(0.87-0.90)$. The sensitivity, specificity, and positive and negative predictive values for the self-screening method were $0.74(0.63-0.82)$, 0.97 (0.95-0.99), $0.86(0.77-0.93)$, and 0.94 (0.91-0.96), respectively, in men. In women, these values were $0.50(0.30-0.70), 0.99(0.98-1), 0.81$ (0.54-0.96), and 0.97 (0.95-0.99), respectively. Conclusion: The self-screening method for assessing cardiovascular risk provided similar results to the standard method. Self-screening had high clinical performance to rule out intermediate or high cardiovascular risk.

Keywords: risk assessment, cardiovascular diseases, preventive medicine, public health, epidemiology, empowerment

\section{Background}

Cardiovascular diseases are the main cause of death in the developed world and are gaining importance in low-income countries. ${ }^{1}$ Nonetheless, a substantial fall in cardiovascular disease mortality has been observed in developed countries, approximately half of which has been attributed to cost-effective evidence-based treatments used in clinical cardiology and half to the crucial role of healthy diet, increased physical activity, and decreased consumption of tobacco and alcohol. ${ }^{2,3}$ These key drivers are increasingly recognized as being potentially powerful, rapid, equitable, and cost-saving. ${ }^{4}$

Currently, the first step in cardiovascular risk screening is the estimation of cardiovascular risk using validated risk functions. ${ }^{5,6}$ This procedure, usually performed in primary 
care settings under the supervision of health professionals, has limitations. ${ }^{5,7}$ For instance, there is a wide gap between expert recommendations and actual preventive practice. ${ }^{8}$ Physicians have been found to have difficulty meeting the international standards even when they strongly believe that preventive care is important and that risk factors for cardiovascular disease can and should be reduced. ${ }^{9,10}$ Moreover, the current screening strategy may not reach young, healthy people, who are less likely to visit primary care settings ${ }^{11}$ but are also the main audience for the preventive message because cumulative exposure to cardiovascular risk factors over time precedes the clinical expression of cardiovascular diseases.

In addition, the trends in coronary heart disease mortality in the USA show a troubling contrast between the steep decrease recently observed in older populations and the small decreases in young populations. ${ }^{12}$ Although the low burden of cardiovascular diseases in younger populations would make it difficult to observe dramatic decreases, the implementation of preventive programs in young people is key to reduce the incidence at older ages. This paradigm may change if individuals can be empowered to assume a leading role in making decisions about their own health. ${ }^{13}$ Thus, the use of a self-screening method to assess cardiovascular risk may help to increase population awareness and shared responsibility for cardiovascular disease prevention.

To better address a key target population for the preventive message, the objective of the present study was to evaluate the validity of a cardiovascular risk self-screening method that includes self-measurement of blood pressure, a point-of-care assessment of lipid profile and glycated hemoglobin, and a self-administered questionnaire (sex, age, diabetes, tobacco consumption), compared with the standard screening (gold standard) conducted by a health professional.

\section{Methods}

In a randomized crossover clinical trial in the city of Girona and surrounding areas (northeastern Spain), individuals were randomly selected from the reference population. Those aged 35-74 who did not present with cardiovascular diseases at baseline were included in the study. Participants were randomly assigned to one of two cardiovascular risk screening sequences: standard screening followed by self-screening or vice versa. Both screening methods were performed the same day and included the eight variables used to estimate cardiovascular risk with the Framingham function, adapted and validated for the Spanish population ${ }^{14}$ using the standard methodology ${ }^{15}$ : sex, age, systolic and diastolic blood pressure, total cholesterol, high-density lipoprotein (HDL) cholesterol, tobacco consumption, and diabetes. The only difference between the screening methods was the active role of the team of trained nurses in the standard screening and their minimal supervision of the self-screening, mainly related to blood capillary extraction and analysis.

We needed a sample size of 900 individuals to estimate a kappa index of 0.8 with $95 \% \mathrm{CI}$, considering that $65 \%$ of the reference population presented with low risk $(<5 \%), 25 \%$ with intermediate risk ( $\geq 5 \%$ and $<10 \%)$, and $10 \%$ with high risk $(\geq 10 \%){ }^{6}$

All participants provided written informed consent before enrollment. The present study was approved by the Clinical Research Ethic Committee of the Parc de Salut Mar (CEIC-PSMAR, \#2014/5815/I) and has been registered in ClinicalTrials.gov (\#NCT02373319).

\section{Blood pressure measurement}

Blood pressure was measured with an automatic blood pressure monitor and a cuff adapted to upper arm perimeter (young, adult, obese) for each participant. After a 5-min rest, two measurements were taken, at least 2 minutes apart, and the lower value was recorded for the study. The cutoff points for hypertension followed the criteria in the Seventh Report of the Joint National Committee. ${ }^{16}$ The team of nurses performed these measures in the standard screening; in the self-screening, computer prompts guided the participants to independently measure and record their blood pressure.

\section{Laboratory tests}

To determine the lipid profile (total cholesterol, HDL cholesterol, and triglycerides) and the glycated hemoglobin in the standard screening procedure, blood was withdrawn in $<60$ seconds after $10-14 \mathrm{~h}$ fasting. Serum sample aliquots were stored at $-80^{\circ} \mathrm{C}$. Total cholesterol and HDL cholesterol concentrations were determined by enzymatic and direct methodologies, respectively (ABX-Horiba, Montpellier, France). When triglycerides were $<300 \mathrm{mg} / \mathrm{dL}$, low-density lipoprotein cholesterol was calculated using the Friedewald formula. Glycated hemoglobin was determined by colorimetry and latex agglutination procedures (ABX-Horiba). All analyses were performed in a central laboratory. When participants used the self-screening methodology, they performed a capillary blood analysis with the Cobas b101 (Roche Diagnostics, Basel, Switzerland) point-of-care device under nurse supervision. Total and HDL cholesterol (ApoB precipitation) were determined by enzymatic methods and glycated hemoglobin by latex agglutination procedure. 


\section{Other variables collected}

Both screening methods collected data on sex, age, educational level, tobacco consumption, and self-reported diabetes and related treatment with self-administered standard questionnaires. Although educational level was not required to estimate the cardiovascular risk, this variable was collected for the assessment of comparability of the two study groups. Diabetes was considered whenever an individual reported a history of the disorder, was being treated with insulin or oral antidiabetic treatments, or presented with a glycated hemoglobin $\geq 6.5 \% .^{17}$

A precision scale of easy calibration was used for weight measurement with participants in underwear. Height was measured with a standard measuring rod, with participants standing barefoot. Body mass index was determined as weight divided by squared height $\left(\mathrm{kg} / \mathrm{m}^{2}\right)$. Waist perimeter was also collected.

\section{Statistical analysis}

All analyses were stratified by sex. Categorical variables were presented as proportions and continuous variables as mean and SD or median and interquartile range when their distribution departed from normal.

To compare the results of the standard and the selfscreening methods, the intraclass correlation coefficient (ICC) and kappa index were estimated for continuous (total and HDL cholesterol, glycated hemoglobin, systolic and diastolic blood pressure, cardiovascular risk) and categorical variables (diabetes), respectively. We also estimated the kappa index in a sensitivity analysis, considering glycemia in the estimate of diabetes prevalence for the standard screening. Additionally, the concordance of lipid measurements and glycated hemoglobin between the ABX-Horiba Pentra autoanalyzer ${ }^{\circledR}$ (standard screening) and the Cobas b10 $1{ }^{\circledR}$ point-of-care device (self-screening) was measured using the $\mathrm{R}^{2}$ coefficient of determination and Bland-Altman plots. ${ }^{18}$ We estimated the Pearson correlation between the two screening methods and compared the distribution in three cardiovascular risk categories (low $<5 \%$, intermediate $\geq 5 \%$ and $<10 \%$, and high $\geq 10 \%$ ) with chi-square tests. We described the intermediate/high-risk individuals identified with each strategy and estimated sensitivity, specificity, and the positive and negative predictive value, likelihood ratios of a positive and a negative test, diagnostic accuracy and odds ratio, Youden Index, and area under the receiver operator characteristics (ROC) curve at a cutoff point $\geq 5 \%$. ${ }^{19}$

All the statistical analyses were performed with the $\mathrm{R}$ Statistical Package (R Foundation for Statistical Computing, Vienna, Austria; V.3.3.2).

\section{Results}

The present study included 937 individuals (52.3\% women) with mean age of 50 years $(\mathrm{SD}=10)$ (Figure 1) and a response rate of $60 \%$. No sex or age differences were found between participants and nonparticipants. Table 1 summarizes the main characteristics of the participants by sex and screening sequence. The additional variables, not used to estimate the cardiovascular risk, have been described using the same stratification in Table S1. The concordance between selfscreening and standard measures was high for all single variables studied (ICC $\geq 0.86$ ), except for glycated hemoglobin in women $(\mathrm{ICC}=0.72)$. The ICCs for cardiovascular risk were

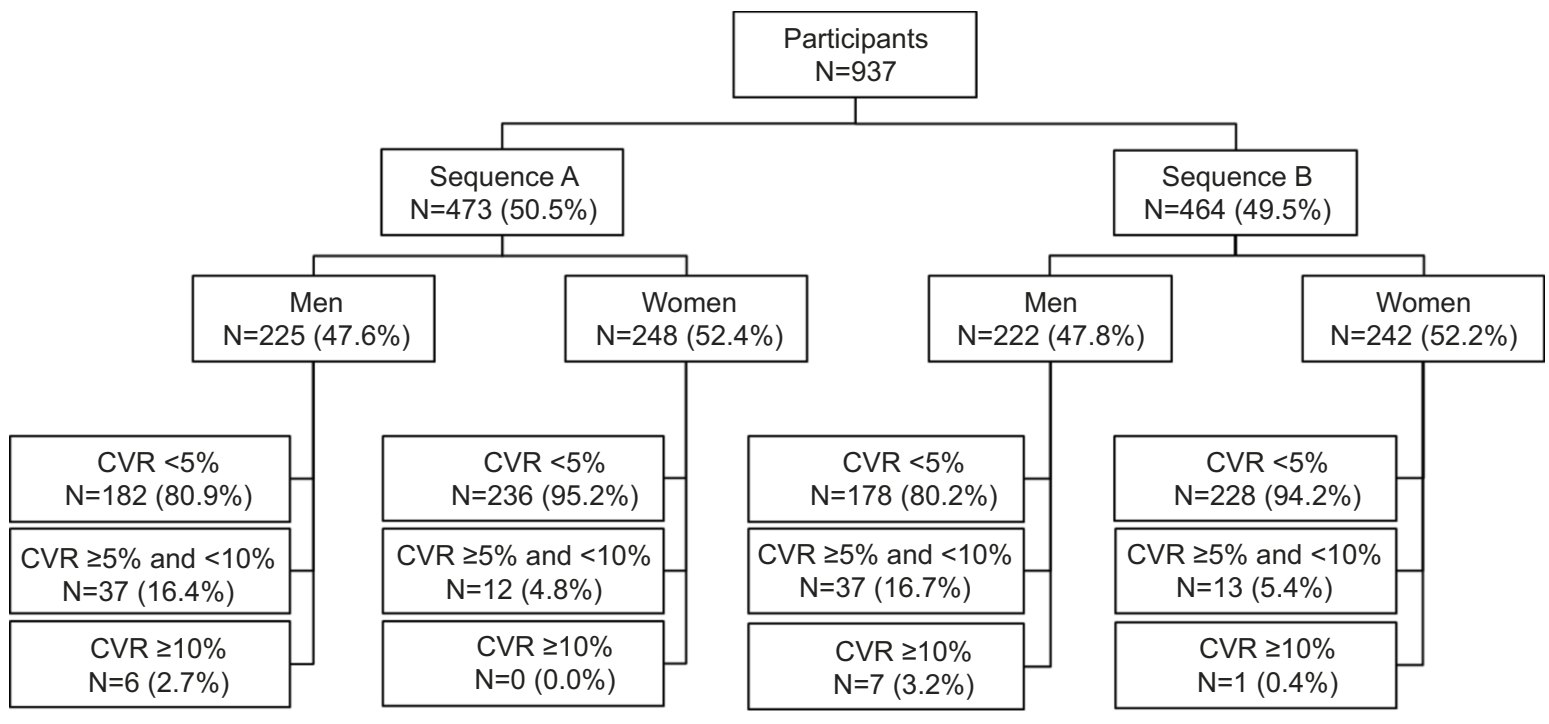

Figure I Flow chart of the participants in the ACRISC Study.

Abbreviation: CVR, cardiovascular risk; ACRISC, self-screening of cardiovascular risk. 
high in both men and women (0.92 [95\% CI: 0.90-0.93] and 0.89 [0.87-0.90], respectively) (Table 2 and Figure 2). The results of the sensitivity analysis using glycemia for the standard screening yielded similar results (kappa index in men and in women: 0.94 and 0.86, respectively). Figures $\mathrm{S} 1-\mathrm{S} 6$ show the linear regression plots with the estimated $\mathrm{R}^{2}$ and the Bland-Altman plots for total and HDL cholesterol and glycated hemoglobin levels as measured with the Pentra autoanalyzer ${ }^{\circledR}$ and Cobas b $101{ }^{\circledR}$ point-of-care device.

The standard and self-screening methods did not differ significantly in their classification of individuals by risk category $(<5 \%, \geq 5 \%$ and $<10 \%$, and $\geq 10 \%)$ with a kappa index $=0.80$ (Figure 3 ).

Self-screening of cardiovascular risk considering a cutoff point $\geq 5 \%$ showed high specificity and negative predictive value in both men and women. The likelihood ratio for a positive test (26.5 in men and 77.3 in women) indicated high probability of increased risk and the likelihood ratio for a negative test showed low probability of increased risk $(0.27$ and 0.50 , respectively). The diagnostic accuracy was also high, pointing out a marked proportion of correctly classified subjects. In addition, the estimates of diagnostic odds ratio, the Youden Index, and the area under the ROC curve showed a satisfactory discriminative power of the self-screening using the $5 \%$ cutoff point (Table 3 ).

\section{Discussion}

The estimation of cardiovascular risk is acknowledged as the first step in cardiovascular prevention, enabling application of the most efficient preventive strategy in each individual.

Table I Participant characteristics by screening sequence

\begin{tabular}{|c|c|c|c|c|}
\hline \multirow[t]{2}{*}{ Variables } & \multicolumn{2}{|l|}{ Men } & \multicolumn{2}{|l|}{ Women } \\
\hline & $\begin{array}{l}\text { Sequence } A \\
(n=225)\end{array}$ & $\begin{array}{l}\text { Sequence B } \\
(n=222)\end{array}$ & $\begin{array}{l}\text { Sequence } A \\
(n=248)\end{array}$ & $\begin{array}{l}\text { Sequence B } \\
(n=242)\end{array}$ \\
\hline Age, mean (SD) & $49(10)$ & $50(10)$ & $50(10)$ & $5 I(I I)$ \\
\hline \multicolumn{5}{|l|}{ Educational level, $n(\%)$} \\
\hline Primary school & $45(20.2)$ & $53(24.0)$ & $56(22.7)$ & $5 I(2 I .2)$ \\
\hline High school & $102(45.7)$ & $93(42.1)$ & $94(38.1)$ & $101(41.9)$ \\
\hline University & $76(34.1)$ & $73(33.0)$ & $96(38.9)$ & $84(34.9)$ \\
\hline \multicolumn{5}{|l|}{ Smoking status, $\mathrm{n}(\%)$} \\
\hline Former smoker & $86(38.2)$ & $79(35.6)$ & $70(28.2)$ & $71(29.3)$ \\
\hline Smoker & $62(27.6)$ & $55(24.8)$ & $43(17.3)$ & $48(19.8)$ \\
\hline Systolic blood pressure $(\mathrm{mmHg})$, mean (SD) & $118(16)$ & $118(15)$ & $105(15)$ & $107(16)$ \\
\hline Diastolic blood pressure $(\mathrm{mmHg})$, mean (SD) & $78(10)$ & $78(10)$ & $71(11)$ & $71(10)$ \\
\hline Total cholesterol (mg/dL), mean (SD) & $211(37)$ & $209(40)$ & 209 (39) & $207(36)$ \\
\hline HDL cholesterol (mg/dL), mean (SD) & $5 I(I I)$ & $50(\mathrm{II})$ & $60(14)$ & $60(13)$ \\
\hline Diabetes, $\mathrm{n}(\%)$ & $19(8.4)$ & $24(10.8)$ & $9(3.6)$ & $13(5.4)$ \\
\hline Glycated hemoglobin (\%), mean (SD) & $5.5(0.6)$ & $5.6(0.8)$ & $5.5(0.4)$ & $5.5(0.4)$ \\
\hline Body mass index, mean (SD) & $27.1(4.2)$ & $27.2(4.1)$ & $26.0(5.0)$ & $25.9(4.6)$ \\
\hline
\end{tabular}

Abbreviation: HDL, high-density lipoprotein.

Table 2 Concordance between self-screening and standard measures needed to estimate cardiovascular risk, stratified by sex

\begin{tabular}{|c|c|c|c|c|c|c|}
\hline \multirow[t]{2}{*}{ Variables } & \multicolumn{3}{|l|}{ Men } & \multicolumn{3}{|l|}{ Women } \\
\hline & $\begin{array}{l}\text { Standard } \\
\text { screening } \\
(n=447)\end{array}$ & $\begin{array}{l}\text { Self-screening } \\
(n=447)\end{array}$ & $\begin{array}{l}\text { Concordance } \\
(95 \% \mathrm{Cl})\end{array}$ & $\begin{array}{l}\text { Standard } \\
\text { screening } \\
(n=490)\end{array}$ & $\begin{array}{l}\text { Self-screening } \\
(n=490)\end{array}$ & $\begin{array}{l}\text { Concordance } \\
(95 \% \mathrm{Cl})\end{array}$ \\
\hline Systolic blood pressure $(\mathrm{mmHg})$, mean (SD) & $118(15)$ & $118(15)$ & $0.86(0.83-0.88)^{\mathrm{a}}$ & $106(16)$ & $106(16)$ & $0.86(0.83-0.88)^{\mathrm{a}}$ \\
\hline Diastolic blood pressure $(\mathrm{mmHg})$, mean (SD) & $78(10)$ & $78(10)$ & $0.88(0.86-0.90)^{\mathrm{a}}$ & $71(10)$ & $73(11)$ & $0.87(0.84-0.89)^{\mathrm{a}}$ \\
\hline Total cholesterol (mg/dL), mean (SD) & $210(38)$ & $200(35)$ & $0.86(0.69-0.92)^{\mathrm{a}}$ & $208(37)$ & $199(34)$ & $0.90(0.74-0.95)^{\mathrm{a}}$ \\
\hline HDL cholesterol (mg/dL), mean (SD) & $5 I(I I)$ & $52(13)$ & $0.91(0.88-0.93)^{\mathrm{a}}$ & $60(13)$ & $64(15)$ & $0.90(0.76-0.95)^{\mathrm{a}}$ \\
\hline Glycated hemoglobin, mean (SD) & $5.6(0.7)$ & $5.7(0.8)$ & $0.91(0.89-0.93)^{\mathrm{a}}$ & $5.5(0.4)$ & $5.6(0.5)$ & $0.72(0.67-0.76)^{\mathrm{a}}$ \\
\hline Diabetes, n (\%) & $43(9.6)$ & $44(9.8)$ & $0.94^{b}$ & $22(4.5 \%)$ & $26(5.3 \%)$ & $0.87^{b}$ \\
\hline Cardiovascular risk, median (IQR) & $\begin{array}{l}2.56 \\
(1.42-4.35)\end{array}$ & $\begin{array}{l}2.25 \\
(1.28-4.07)\end{array}$ & $\begin{array}{l}0.92 \\
(0.90-0.93)^{a}\end{array}$ & $\begin{array}{l}1.14 \\
(0.61-2.10)\end{array}$ & $\begin{array}{l}1.10 \\
(0.56-2.00)\end{array}$ & $0.89(0.87-0.90)^{\mathrm{a}}$ \\
\hline
\end{tabular}

Notes: antraclass coefficient correlation; 'kappa index.

Abbreviations: HDL, high-density lipoprotein; IQR, interquartile range. 

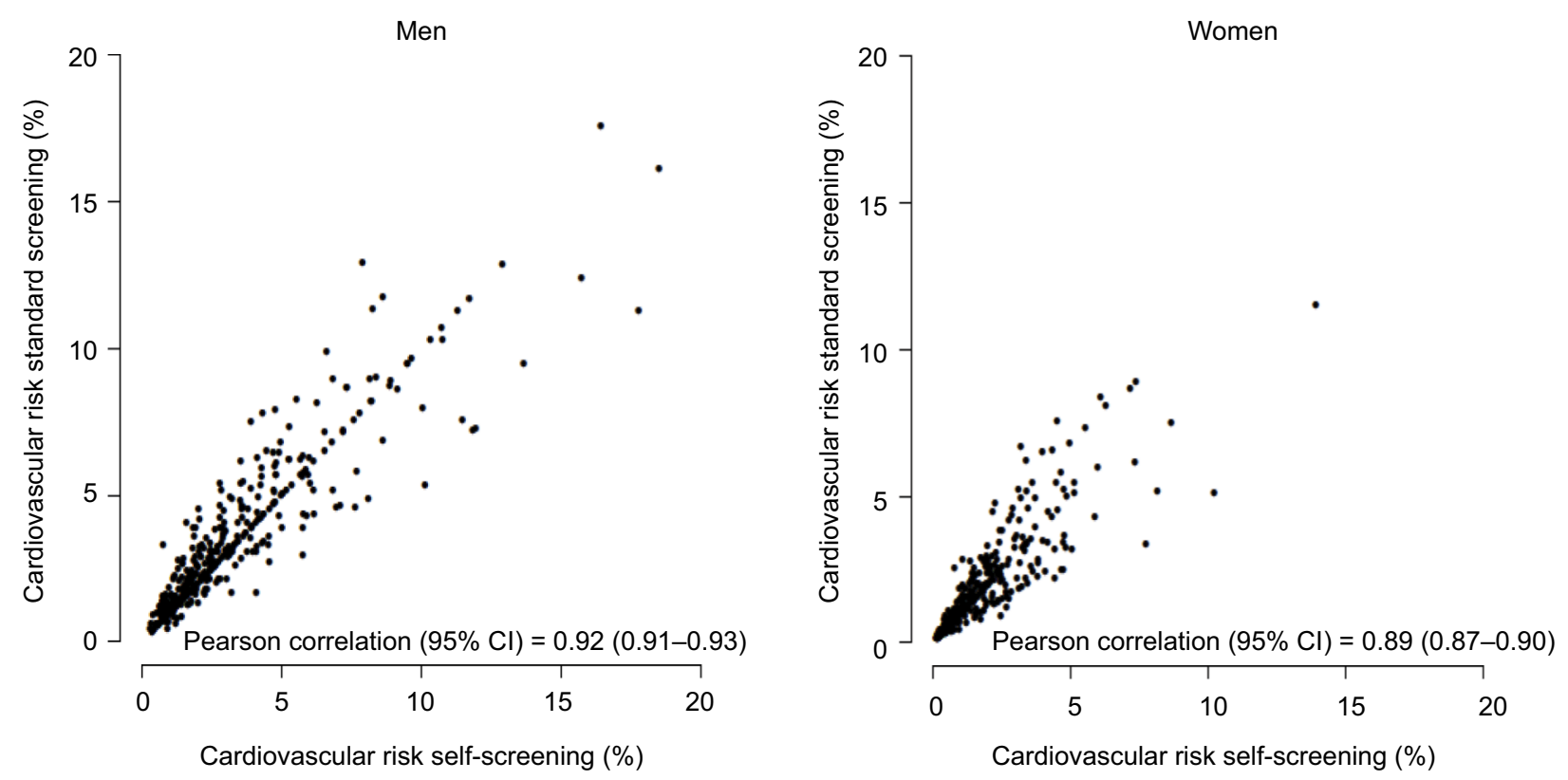

Figure 2 Correlation between standard screening and self-screening measures of cardiovascular risk

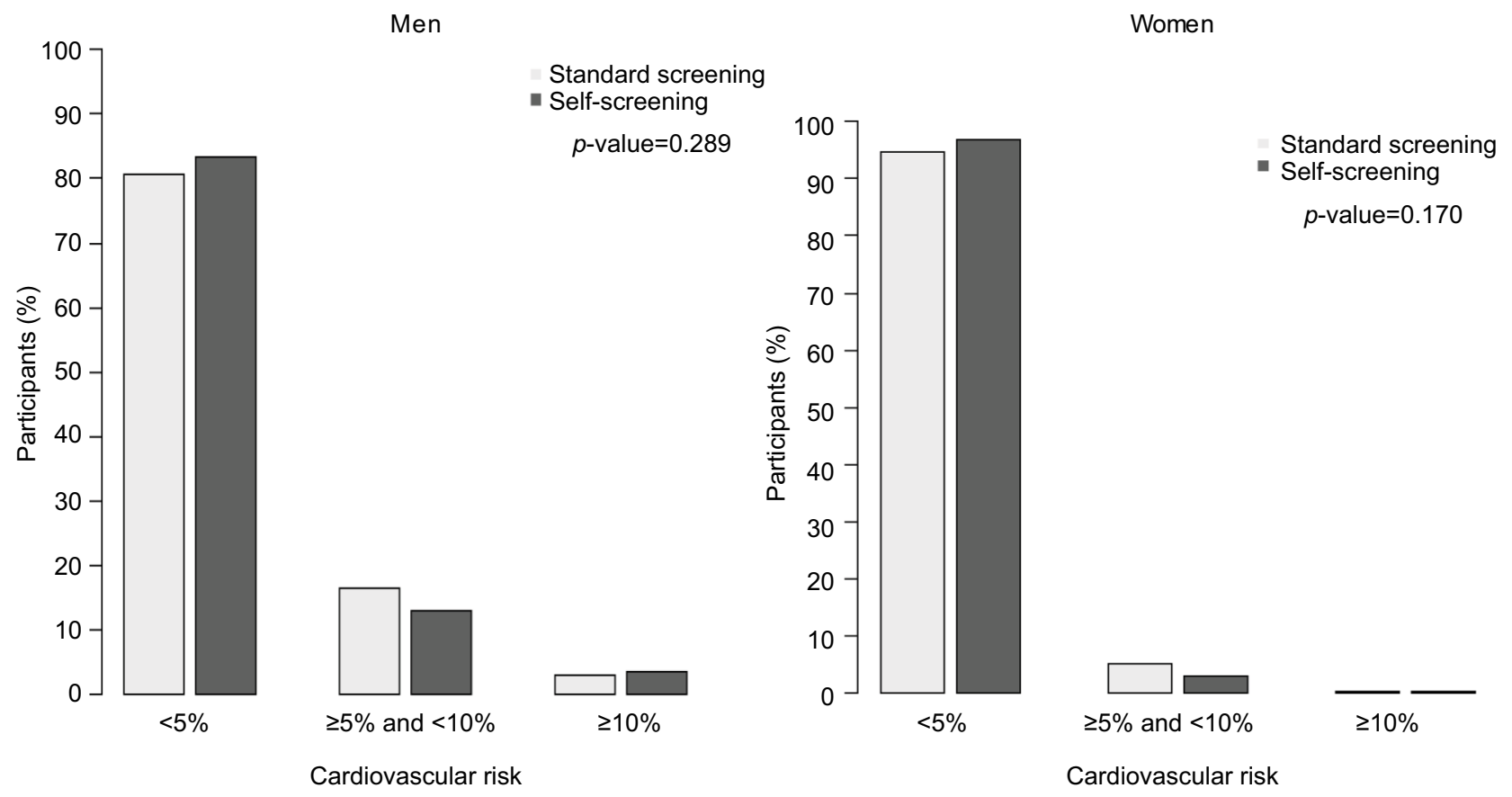

Figure 3 Distribution of participants by cardiovascular risk category according to standard screening and self-screening results.

The innovative self-screening method proposed empowers the individual to measure and record the eight health variables (blood pressure, lipid profile, glycated hemoglobin, age, sex, tobacco consumption, diabetes) required to assess cardiovascular risk, with minimal supervision by a health professional. As results obtained were similar to the goldstandard clinical method, healthy people who do not frequent clinical settings could increase their awareness and avoid preventable cardiovascular disease by conducting their own risk assessment at their convenience.

\section{Empowerment for the prevention of cardiovascular diseases}

Population empowerment is considered a key principle of health promotion by the World Health Organization. ${ }^{20}$ This concept emphasizes that all persons have strengths and 
Table 3 Sensitivity, specificity, positive and negative predictive values, diagnostic accuracy and odds, Youden's Index, and area under the ROC curve of self-screening compared with standard screening, stratified by sex

\begin{tabular}{|c|c|c|c|c|}
\hline \multirow[t]{3}{*}{ Clinical performance } & \multicolumn{4}{|c|}{ Self-screening of cardiovascular risk $\geq \mathbf{5} \%$} \\
\hline & \multicolumn{2}{|l|}{ Men } & \multicolumn{2}{|l|}{ Women } \\
\hline & Estimation & $95 \%$ confidence interval & Estimation & $\mathbf{9 5} \%$ confidence interva \\
\hline Observed prevalence & 0.19 & $0.16-0.23$ & 0.05 & $0.03-0.08$ \\
\hline Estimated prevalence & 0.17 & $0.13-0.20$ & 0.03 & $0.02-0.05$ \\
\hline Sensitivity, \% & 0.74 & $0.63-0.82$ & 0.50 & $0.30-0.70$ \\
\hline Specificity, \% & 0.97 & $0.95-0.99$ & 0.99 & $0.98-1.00$ \\
\hline Positive predictive value, $\%$ & 0.86 & $0.77-0.93$ & 0.81 & $0.54-0.96$ \\
\hline Negative predictive value, $\%$ & 0.94 & $0.91-0.96$ & 0.97 & $0.95-0.99$ \\
\hline Likelihood ratio of a positive test & 26.5 & $14.2-49.4$ & 77.3 & $23.5-254.6$ \\
\hline Likelihood ratio of a negative test & 0.27 & $0.19-0.39$ & 0.50 & $0.34-0.74$ \\
\hline Diagnostic accuracy & 0.93 & $0.90-0.95$ & 0.97 & $0.95-0.98$ \\
\hline Diagnostic odds ratio & 97.4 & $44.3-2 \mid 4.3$ & 153.7 & $39.0-605.4$ \\
\hline Youden's Index & 0.71 & $0.58-0.81$ & 0.49 & $0.28-0.70$ \\
\hline Area under the ROC curve & 0.85 & $0.81-0.90$ & 0.75 & $0.65-0.84$ \\
\hline
\end{tabular}

Abbreviation: ROC, receiver operator characteristics.

providing appropriate resources enhances these strengths. This focus on lifestyle choices and personal responsibility has the potential to change how healthy people avoid preventable cardiovascular diseases as well as other chronic diseases and could indirectly promote choices of healthful activities. Recent reports have identified two approaches, improvement of individual patient skills and transfer of power and decision-making authority about interventions to patients, as effective empowerment strategies. ${ }^{21}$ The present study aimed to validate an easy procedure to self-collect eight variables of general interest (age, sex, tobacco consumption, diabetes, systolic and diastolic blood pressure, and total and HDL cholesterol) to estimate cardiovascular risk. As in previous studies, lifetime risk increased exponentially after 55 years of age according to the number of cardiovascular risk factors above the recommended levels. ${ }^{22}$ Additionally, the combination of such variables in a cardiovascular risk score (e.g., Framingham-REGICOR score validated for the Spanish population) provides valid information about an individual's 10 -year cardiovascular risk. ${ }^{6}$ General practitioners play an important role in the primary prevention of cardiovascular disease; however, mhealth has the potential to promote patient self-management, as a complement to the doctor's intervention, and encourage greater participation in medical decision making. Our solution could be used together with usual office consultation and remote patient monitoring to implement a health care model including personalized health care delivery with an early diagnosis and treatment if needed. Although our self-screening method is not the first to be described in the literature, ${ }^{23,24}$ its novelty is the self-collection of objective variables (e.g., blood pressure, lipid profile, weight) with validated devices.

\section{Prevention of cardiovascular disease in healthy individuals}

Numerous innovations in health information technology are empowering individuals to assume a more active role in monitoring and managing their health and wellness, as well as their chronic conditions and therapeutic regimens. ${ }^{25}$ The effectiveness of self-management in chronic diseases has been analyzed through traditional education programs or, more recently, through mobile apps and other information and communication technologies. ${ }^{25-27}$ Regarding the latter, innovative approaches have been reported for overcoming obesity, ${ }^{28}$ encouraging regular physical activity ${ }^{29}$ and smoking cessation, ${ }^{30}$ control of hypertension ${ }^{31}$ and dyslipidemia, ${ }^{32}$ and treating diabetes mellitus. ${ }^{33}$ However, a major limitation of these innovative technologies is the absence of published evaluations. The present crossover clinical trial validates a new self-screening system that aims to empower individuals to assess their own cardiovascular risk. This device also could be used to estimate the risk of other chronic diseases such as cancer $^{34-36}$ or cognitive decline ${ }^{37}$ in which the assessed comorbidities (hypertension, diabetes, obesity, dyslipidemia) play a crucial role. The added value of this validated procedure is the stratification of population risk, as users become aware about their own health and the most efficient strategies for preventing chronic diseases. Self-screening for cardiovascular risk yielded remarkable specificity and negative predictive values compared with the gold standard. In addition, there was high concordance between methods in the estimated cardiovascular risk category. 


\section{Limitations}

Risk estimation is considered the best tool to prioritize primary prevention strategies. ${ }^{5,8}$ Our crossover clinical trial aimed to validate a new self-screening method in a population-based sample that covered a very wide range of cardiovascular risk. Participants were randomized to one of two sequences of risk assessment (i.e., the current gold standard followed by selfscreening or vice versa) and all four risk measurements (systolic and diastolic blood pressure, total and HDL cholesterol) were collected with both methodologies. Selection bias may affect the present study, but is likely to be modest because it was population-based and participants were not selected on the basis of cardiovascular risk. In addition, the low cardiovascular risk traditionally observed in Mediterranean women ${ }^{38}$ and also reflected in our analysis may explain the low sensitivity of the self-screening (50\%) to rule out intermediate or high cardiovascular risk. Despite the availability of a cardiovascular risk score with no laboratory and blood pressure determinations that has been validated for the Spanish population, ${ }^{39}$ we preferred to validate the self-screening procedure using the more accurate Framingham-REGICOR cardiovascular risk chart. ${ }^{6,14}$ The aim of the study was to assess the validity of a cardiovascular risk self-screening method by comparing the results with a gold standard (current clinical practice). However, we did not test whether the self-screening had an effect on health outcomes. Further randomized clinical trials should be performed to answer this question. Finally, although our aim is to empower individuals to monitor their cardiovascular health, preferably at home, the blood capillary extraction and analysis must be supervised by a health care professional. Thus, the present version of the system must be implemented at a centralized location that is readily accessible to the target population (e.g., pharmacies, primary health care settings).

\section{Future directions}

This self-screening system encourages users to take responsibility for their own health and well-being. Although health care professionals are ideally positioned to provide advice and education on risk factors and lifestyle modifications to people living with chronic conditions, a large part of the healthy population seldom visits a health care provider. Thus, a validated self-management system based on objective measurements empowers healthy people to avoid preventable cardiovascular and other chronic diseases. Our innovative method makes it possible to expand screening coverage to healthy populations, encouraging personal empowerment and increasing self-awareness of individual risk. A feedback strategy could be combined with tailored lifestyle recom- mendations to improve adherence to healthier habits and encourage effective disease prevention strategies.

\section{Conclusion}

The self-screening method for assessing cardiovascular risk provided similar results to the standard method. In addition, this innovative system showed high clinical performance to rule out intermediate or high cardiovascular risk (i.e., $\geq 5 \%$ ).

\section{Acknowledgments}

The authors wish to thank Marta Cabañero, Leny Franco, Neus Guday, Montse Peris, Martina Sidera, and Susanna Tello for their contribution to the data collection and management of this project and appreciate the revision of the English text by Elaine Lilly, Ph D. This study was partially financed with unconditional support from Roche Diagnostics and by Spain's Ministry of Economy and Competitiveness through the Carlos III Health Institute FEDER (CM12/03287, CPII17/00012, and FIS14/00449).

\section{Author contributions}

All authors made substantial contributions to conception and design, acquisition of data, or analysis and interpretation of data; took part in drafting the article or revising it critically for important intellectual content; gave final approval of the version to be published; and agree to be accountable for all aspects of the work.

\section{Disclosure}

The authors report no conflicts of interest in this work.

\section{References}

1. World Health Statistics. Monograph on the Internet. Geneva: World Health Organization. Available from: https://apps.who.int/infobase/. Accessed January 272017.

2. Capewell S, Ford ES, Croft JB, Critchley JA, Greenlund KJ, Labarthe DR. Cardiovascular risk factor trends and potential for reducing coronary heart disease mortality in the United States of America. Bull World Health Organ. 2010;88(2):120-130.

3. Flores-Mateo G, Grau M, O’Flaherty M, et al. [Analyzing the coronary heart disease mortality decline in a Mediterranean population: Spain 1988-2005]. Rev Esp Cardiol. 2011;64(11):988-996. Spanish.

4. O'Flaherty M, Buchan I, Capewell S. Contributions of treatment and lifestyle to declining CVD mortality: why have CVD mortality rates declined so much since the 1960s? Heart. 2013;99(3):159-162.

5. Grau M, Marrugat J. Risk functions and the primary prevention of cardiovascular disease. Rev Esp Cardiol. 2008;61(4):404-416.

6. Marrugat J, Vila J, Baena-Díez JM, et al. [Relative validity of the 10-year cardiovascular risk estimate in a population cohort of the REGICOR study]. Rev Esp Cardiol. 2011;64(5):385-394. Spanish.

7. McKee G, Kerins M, Hamilton G, et al. Barriers to ESC guideline implementation: results of a survey from the European Council on Cardiovascular Nursing and Allied Professions (CCNAP). Eur J Cardiovasc Nurs. 2017;16(8):678-686. 
8. Piepoli MF, Hoes AW, Agewall S, et al. 2016 European Guidelines on cardiovascular disease prevention in clinical practice: the Sixth Joint Task Force of the European Society of Cardiology and Other Societies on Cardiovascular Disease Prevention in Clinical Practice. Eur Heart J. 2016;37(29):2315-2381.

9. Gjelsvik B. Conflicts and dilemmas in prevention of cardiovascular disease. The new, Norwegian guidelines--a new approach to risk management. Eur J Gen Pract. 2012;18(1):56-62.

10. Vancheri F, Strender LE, Backlund LG. General practitioners' coronary risk estimates, decisions to start lipid-lowering treatment, gender and length of clinical experience: their interactions in primary prevention. Prim Health Care Res Dev. 2013;14(4):394-402.

11. Catalán-Ramos A, Verdú JM, Grau M, et al. Population prevalence and control of cardiovascular risk factors: what electronic medical records tell us. Aten Primaria. 2014;46(1):15-24.

12. Wilmot KA, O'Flaherty M, Capewell S, Ford ES, Vaccarino V. Coronary heart disease mortality declines in the United States from 1979 through 2011: evidence for stagnation in young adults, especially women. Circulation. 2015;132(11):997-1002.

13. Feigin VL, Norrving B, Mensah GA. Primary prevention of cardiovascular disease through population-wide motivational strategies: insights from using smartphones in stroke prevention. BMJ Glob Health. 2017;2(2):e000306.

14. Marrugat J, Subirana I, Comín E, et al; VERIFICA Investigators. Validity of an adaptation of the Framingham cardiovascular risk function: the VERIFICA Study. J Epidemiol Community Health. 2007;61(1): 40-47.

15. Manual of The MONICA Project [Manual on the Internet]. Geneva: World Health Organisation; 2000. Available from: http://www.ktl.fi/ publications/monica/manual/index.htm. Accessed January 8, 2017.

16. Chobanian AV, Bakris GL, Black HR, et al; Joint National Committee on Prevention, Detection, Evaluation, and Treatment of High Blood Pressure. National Heart, Lung, and Blood Institute; National High Blood Pressure Education Program Coordinating Committee. Seventh report of the Joint National Committee on Prevention, Detection, Evaluation, and Treatment of High Blood Pressure. Hypertension. 2003;42(6):1206-1252.

17. Sacks DB, Arnold M, Bakris GL, et al; National Academy of Clinical Biochemistry. Guidelines and recommendations for laboratory analysis in the diagnosis and management of diabetes mellitus. Diabetes Care. 2011;34(6):e61-e99.

18. Bland JM, Altman DG. Statistical methods for assessing agreement between two methods of clinical measurement. Lancet. 1986;1:307-310.

19. Šimundić AM. Measures of diagnostic accuracy: basic definitions. EJIFCC. 2009;19(4):203-211.

20. Woodall J, Raine G, South J, Warwick-Booth L. Empowerment and Health \& Well-Being: Evidence Review. Leeds: Centre for Health Promotion Research, Leeds Metropolitan University; 2010.

21. Wallerstein $\mathrm{N}$. What is the evidence on effectiveness of empowerment to improve health? 2006. Copenhagen: WHO Regional Office for Europe (Health Evidence Network report. Available from: http://www.euro.who. int/Document/E88086.pdf. Accessed October 1, 2017.

22. Berry JD, Dyer A, Cai X, et al. Lifetime risks of cardiovascular disease. $N$ Engl J Med. 2012;366(4):321-329.
23. Neufingerl N, Cobain MR, Newson RS. Web-based self-assessment health tools: who are the users and what is the impact of missing input information? J Med Internet Res. 2014;16(9): 215.

24. Patel RS, Lagord C, Waterall J, Moth M, Knapton M, Deanfield JE. Online self-assessment of cardiovascular risk using the Joint British Societies (JBS3)-derived heart age tool: a descriptive study. BMJOpen. 2016;6(9):e011511.

25. Burke LE, Ma J,Azar KM, et al. Current science on consumer use of mobile health for cardiovascular disease prevention: a scientific statement from the American Heart Association. Circulation. 2015;132(12):1157-1213.

26. Warsi A, Wang PS, LaValley MP, Avorn J, Solomon DH. Selfmanagement education programs in chronic disease: a systematic review and methodological critique of the literature. Arch Intern Med. 2004;164(15):1641-1649.

27. Kim BY, Lee J. Smart devices for older adults managing chronic disease: a scoping review. JMIR Mhealth Uhealth. 2017;5(5):e69.

28. Siopis G, Chey T, Allman-Farinelli M. A systematic review and metaanalysis of interventions for weight management using text messaging. J Hum Nutr Diet. 2015;28(Suppl 2):1-15.

29. Bort-Roig J, Gilson ND, Puig-Ribera A, Contreras RS, Trost SG. Measuring and influencing physical activity with smartphone technology: a systematic review. Sports Med. 2014;44(5):671-686.

30. Whittaker R, McRobbie H, Bullen C, Borland R, Rodgers A, Gu Y. Mobile phone-based interventions for smoking cessation. Cochrane Database Syst Rev. 2012;11:CD006611.

31. Uhlig K, Patel K, Ip S, Kitsios GD, Balk EM. Self-measured blood pressure monitoring in the management of hypertension: a systematic review and meta-analysis. Ann Intern Med. 2013;159(3):185-194.

32. Dekkers JC, van Wier MF, Ariëns GA, et al. Comparative effectiveness of lifestyle interventions on cardiovascular risk factors among a Dutch overweight working population: a randomized controlled trial. $B M C$ Public Health. 2011;11(1):49.

33. Pal K, Eastwood SV, Michie S, et al. Computer-based diabetes selfmanagement interventions for adults with type 2 diabetes mellitus. Cochrane Database Syst Rev. 2013;(3):CD008776.

34. Koene RJ, Prizment AE, Blaes A, Konety SH. Shared risk factors in cardiovascular disease and cancer. Circulation. 2016;133(11):1104-1114.

35. Baena-Díez JM, Peñafiel J, Subirana I, et al. Risk of cause-specific death in individuals with diabetes: a competing risks analysis. Diabetes Care. 2016;39(11):1987-1995.

36. Barroso M, Goday A, Ramos R, et al; FRESCO Investigators. Interaction between cardiovascular risk factors and body mass index and 10-year incidence of cardiovascular disease, cancer death, and overall mortality. Prev Med. 2018;107:81-89.

37. Srinivasa RN, Rossetti HC, Gupta MK, et al. Cardiovascular risk factors associated with smaller brain volumes in regions identified as early predictors of cognitive decline. Radiology. 2016;278(1):198-204.

38. Grau M, Elosua R, Cabrera de León A, et al. Cardiovascular risk factors in Spain in the first decade of the 21 st century, a pooled analysis with individual data from 11 population-based studies: the DARIOS study. Rev Esp Cardiol. 2011;64(4):295-304.

39. Marrugat J, Subirana I, Ramos R, et al; FRESCO Investigators. Derivation and validation of a set of 10-year cardiovascular risk predictive functions in Spain: the FRESCO Study. Prev Med. 2014;61:66-74. 


\section{Supplementary materials}

Table SI Participant characteristics (additional variables) by screening sequence

\begin{tabular}{|c|c|c|c|c|}
\hline \multirow[t]{2}{*}{ Variables } & \multicolumn{2}{|l|}{ Men } & \multicolumn{2}{|l|}{ Women } \\
\hline & $\begin{array}{l}\text { Sequence A } \\
(n=225)\end{array}$ & $\begin{array}{l}\text { Sequence B } \\
(n=222)\end{array}$ & $\begin{array}{l}\text { Sequence } A \\
(n=248)\end{array}$ & $\begin{array}{l}\text { Sequence B } \\
(n=242)\end{array}$ \\
\hline \multicolumn{5}{|l|}{ Family history, n (\%) } \\
\hline Coronary death & $22(9.8)$ & $30(13.5)$ & $26(10.5)$ & $27(11.2)$ \\
\hline Stroke & $37(16.4)$ & $42(18.9)$ & $47(19.0)$ & $56(23.1)$ \\
\hline Intermittent claudication & $6(2.7)$ & $14(6.3)$ & $13(5.2)$ & $20(8.3)$ \\
\hline Waist circumference (cm), mean (SD) & $98.9(7.0)$ & 99.1 (6.8) & I0I.I (9.2) & $100.4(8.1)$ \\
\hline LDL cholesterol (mg/dL), mean (SD) & $136(38)$ & 137 (39) & $133(33)$ & $130(3 \mid)$ \\
\hline Triglycerides (mg/dL), mean (SD) & $91(66-119)$ & $89(66-123)$ & $69(54-98)$ & $74(56-101)$ \\
\hline Non-HDL cholesterol (mg/dL), mean (SD) & $160(37)$ & $159(39)$ & 149 (37) & 147 (34) \\
\hline Total/HDL cholesterol, mean (SD) & $4.3(1.0)$ & $4.3(1.2)$ & $3.6(1.0)$ & $3.6(0.9)$ \\
\hline LDL/HDL cholesterol, mean (SD) & $2.7(0.9)$ & $2.8(1.0)$ & $2.3(0.8)$ & $2.3(0.7)$ \\
\hline Triglycerides/HDL cholesterol, mean (SD) & $2.3(1.6)$ & $2.3(1.9)$ & $1.5(1.1)$ & $\mathrm{I} .5(\mathrm{I} .0)$ \\
\hline Glycemia (mg/dL), mean (SD) & $93(87-100)$ & $94(89-101)$ & $89(83-96)$ & $89(83-96)$ \\
\hline History of diabetes, n (\%) & $15(6.7)$ & $22(10.0)$ & $7(3.1)$ & $12(5.5)$ \\
\hline History of hypertension, $\mathrm{n}(\%)$ & $60(27.0)$ & $68(31.2)$ & $36(14.8)$ & $42(17.4)$ \\
\hline
\end{tabular}

Abbreviations: HDL, high-density lipoprotein; LDL, low-density lipoprotein.
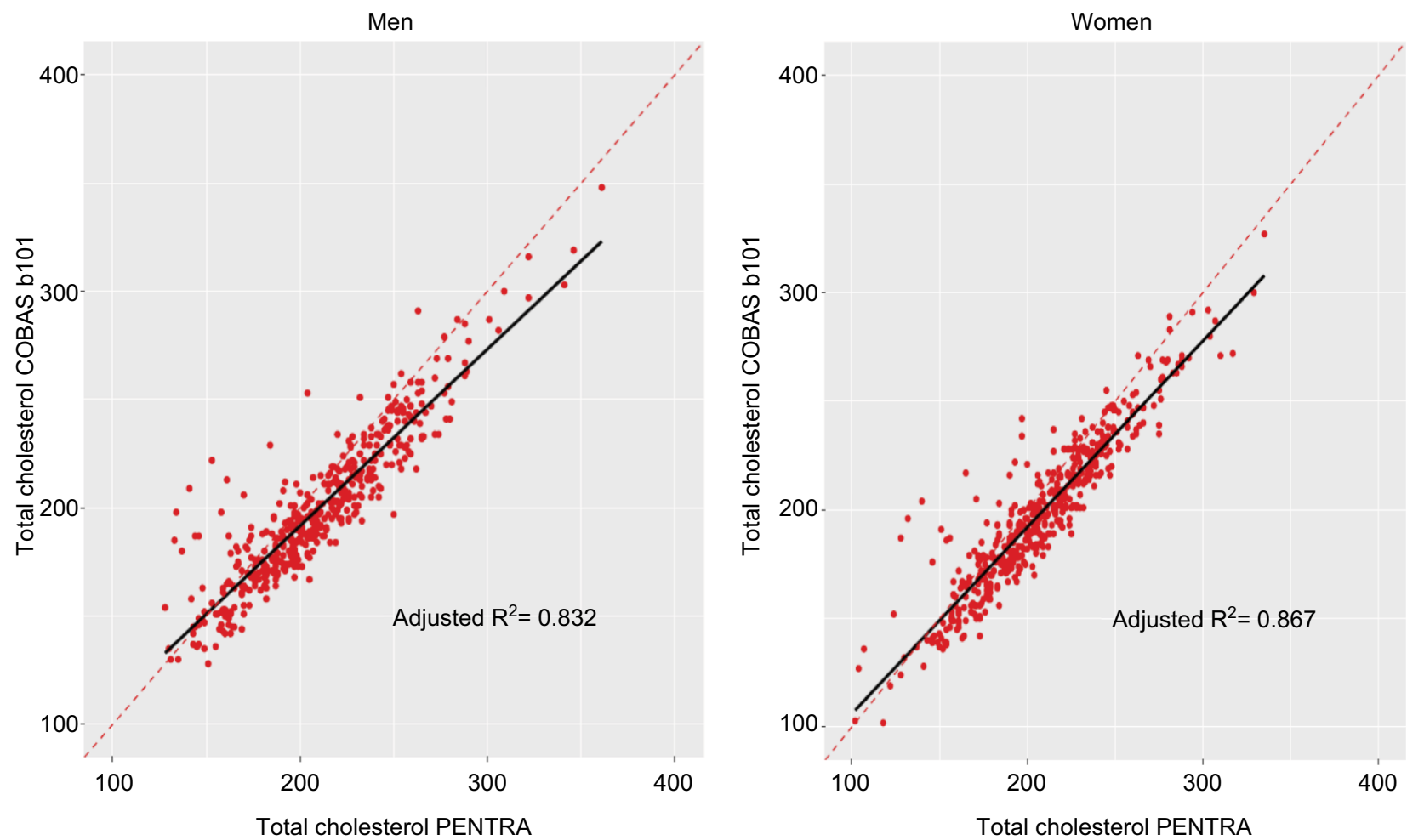

Figure SI Linear regression analysis for total cholesterol $(\mathrm{mg} / \mathrm{dL})$ by sex. 

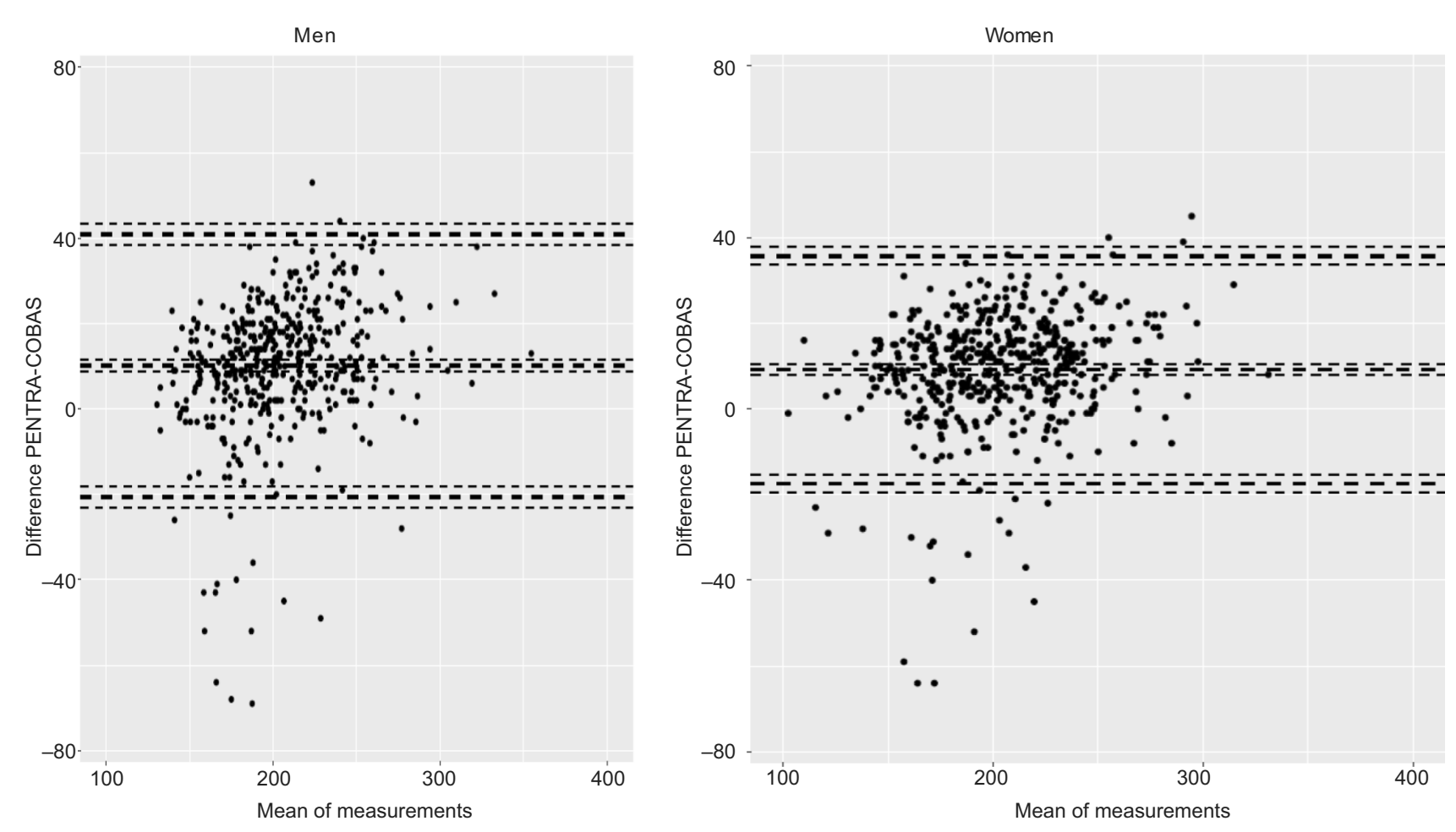

Figure S2 Bland-Altman plot for total cholesterol ( $\mathrm{mg} / \mathrm{dL})$.
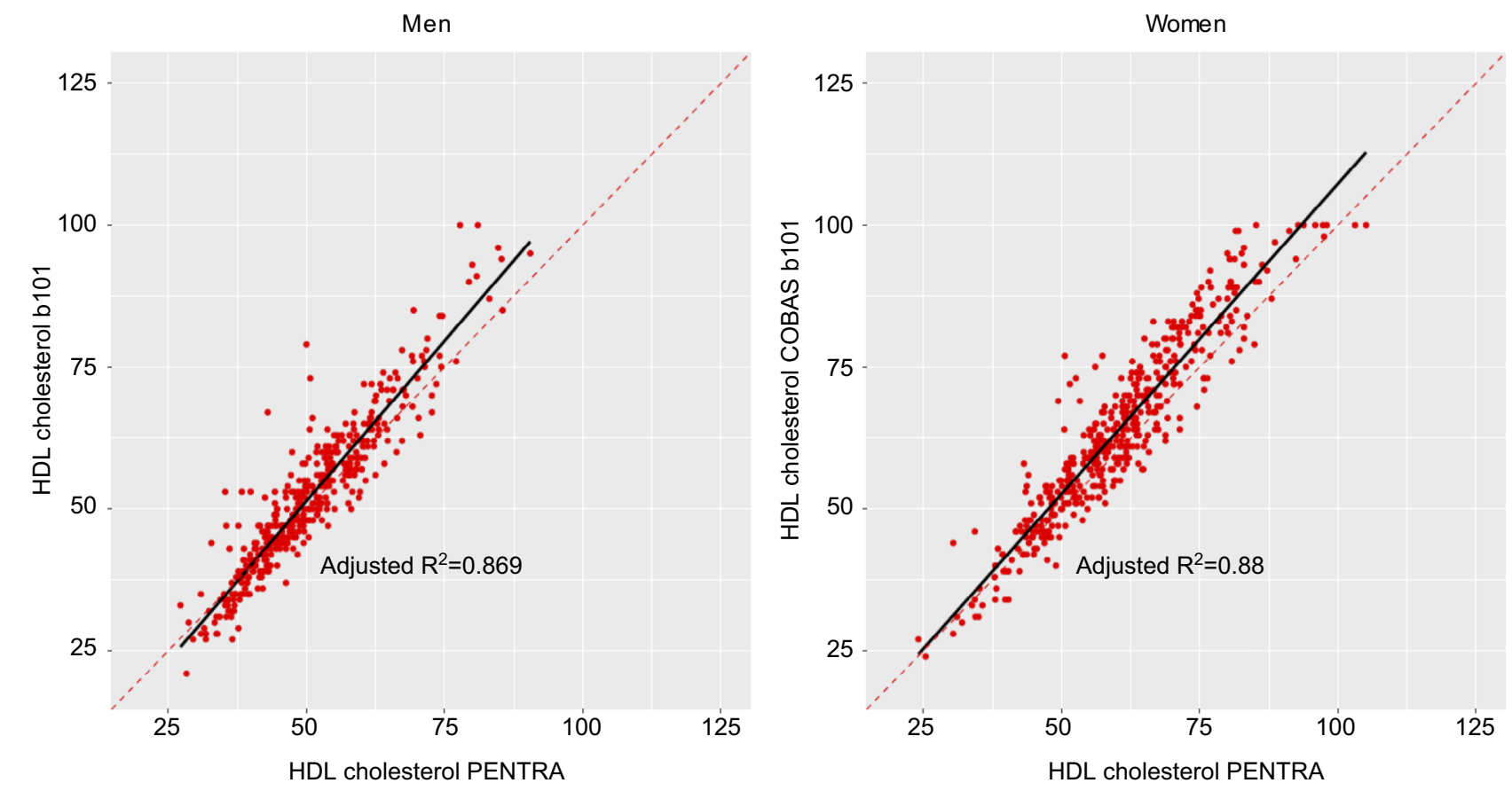

Figure S3 Linear regression analysis for HDL cholesterol $(\mathrm{mg} / \mathrm{dL})$ by sex. Abbreviation: HDL, high-density lipoprotein. 

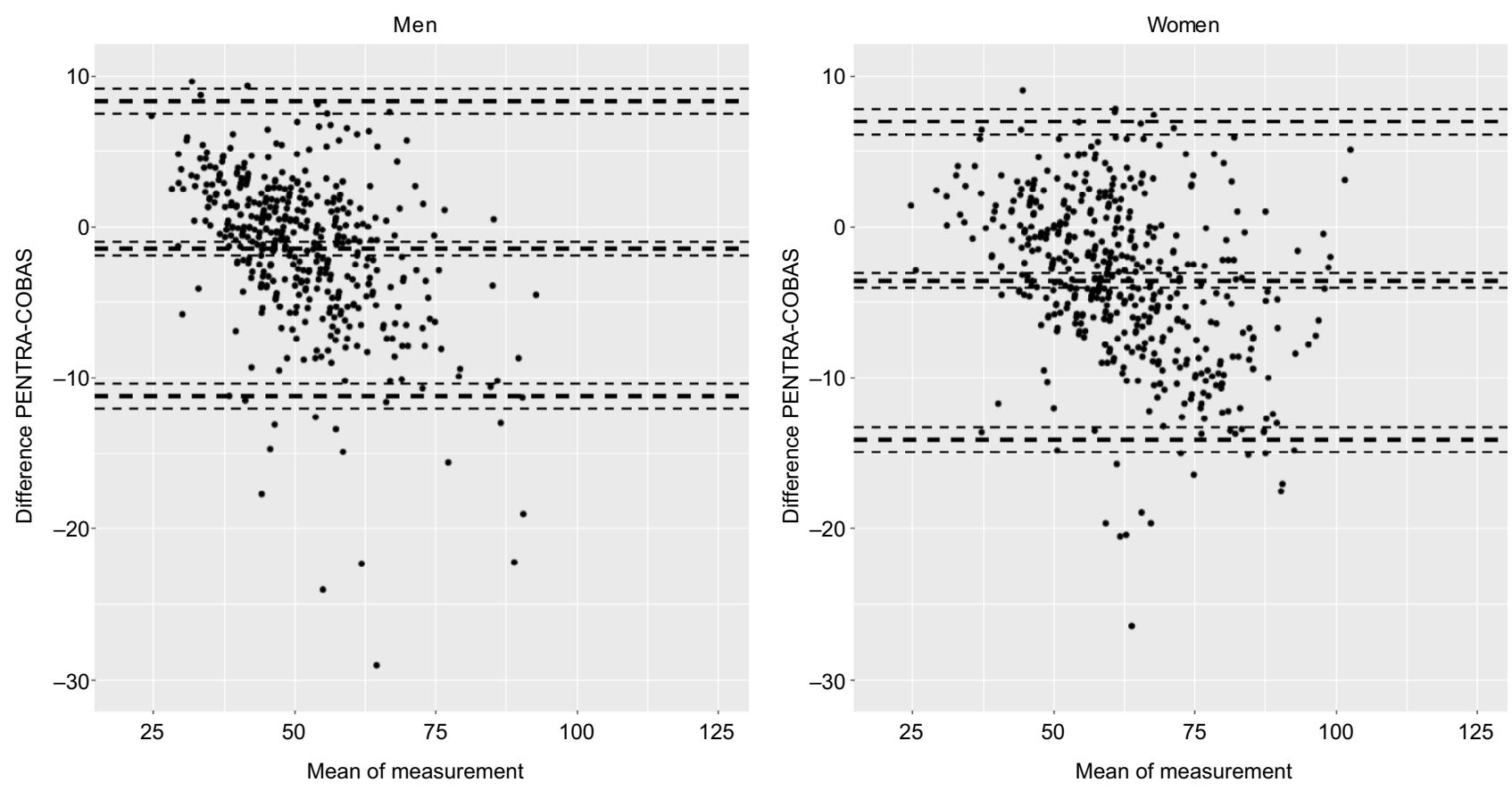

Figure S4 Bland-Altman plot for HDL cholesterol ( $\mathrm{mg} / \mathrm{dL}$ ).

Abbreviation: HDL, high-density lipoprotein.
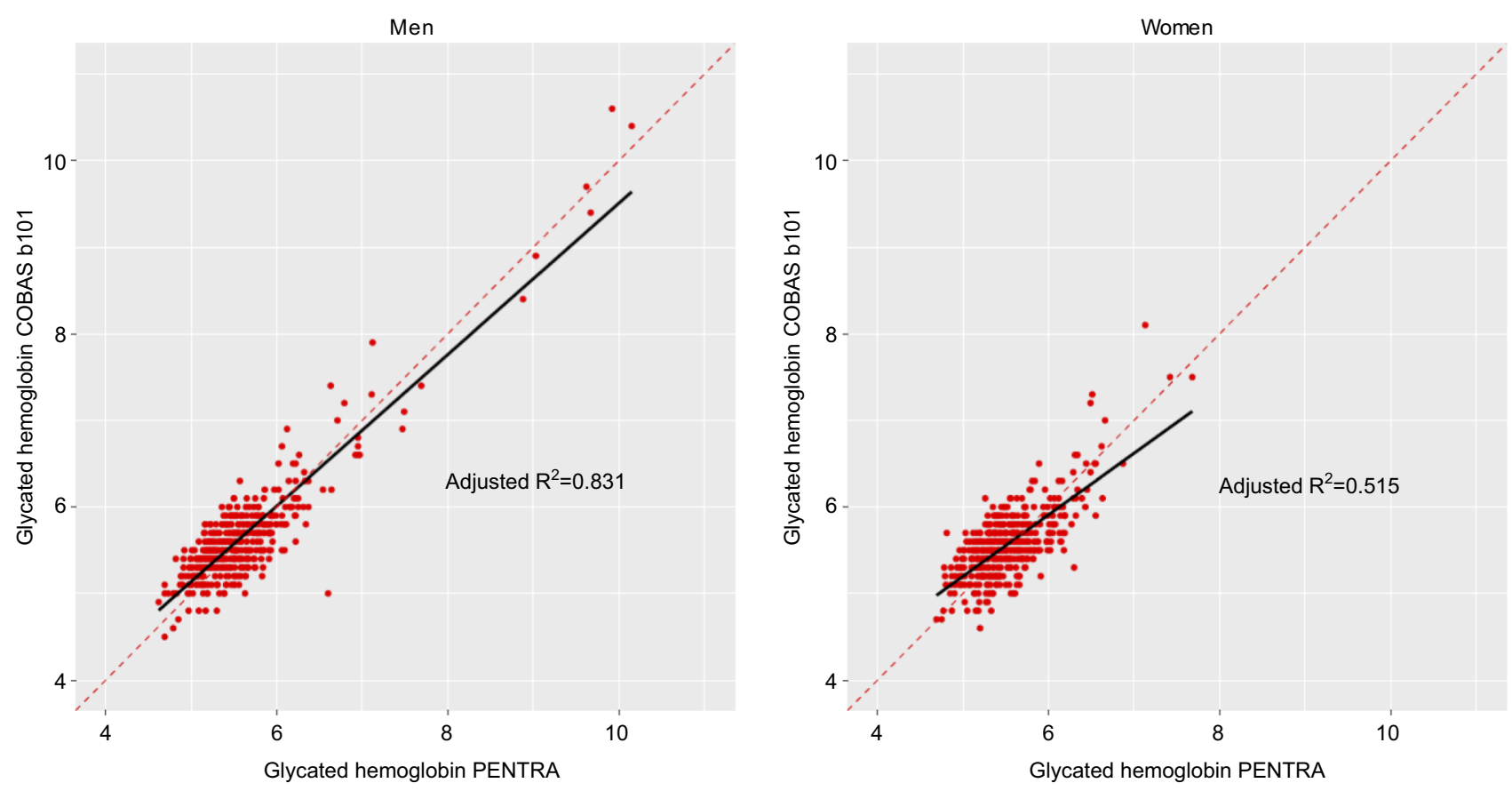

Figure S5 Linear regression analysis for glycated hemoglobin (\%) by sex. 

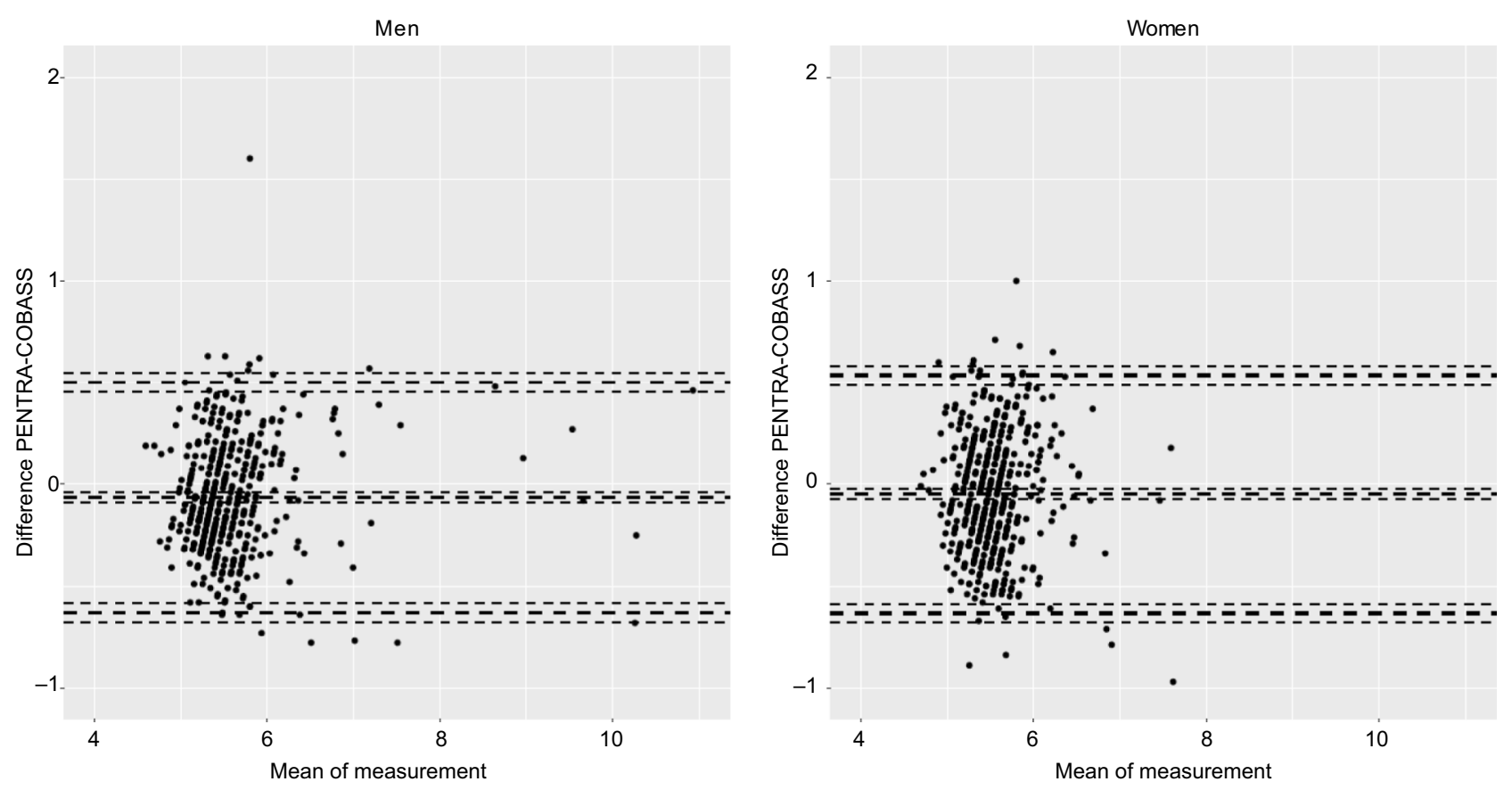

Figure S6 Bland-Altman plot for glycated hemoglobin (\%).

\section{Publish your work in this journal}

Clinical Epidemiology is an international, peer-reviewed, open access, online journal focusing on disease and drug epidemiology, identification of risk factors and screening procedures to develop optimal preventative initiatives and programs. Specific topics include: diagnosis, prognosis, treatment, screening, prevention, risk factor modification, ogy and biostatistical methods, and evaluation of guidelines, translational medicine, health policies and economic evaluations. The manuscript management system is completely online and includes a very quick and fair peer-review system, which is all easy to use. 